\title{
Administrative Resilience in the Face of Natural Disasters: Empirical Evidence from Bangladesh
}

\author{
Md Nazirul Islam Sarker ${ }^{1 *}$, Min Wu ${ }^{1}$, GM Monirul Alam², Roger C Shouse ${ }^{1,3}$ \\ ${ }^{1}$ School of Public Administration, Chengdu, People's Republic of China \\ ${ }^{2}$ Faculty of Agricultural Economics and Rural Development, Bangabandhu Sheikh Mujibur Rahman \\ Agricultural University, Gazipur, Bangladesh \\ ${ }^{3}$ Department of Education Policy Studies, Pennsylvania State University, University Park, United States
}

Received: 6 April 2019

Accepted: 20 May 2019

\begin{abstract}
Administrative resilience is a key tool to stimulate an administrative system to protect, save, and reduce livelihood vulnerability in the face of natural hazards. The main purpose of this study is to explore the potential of administrative resilience to improve livelihood resilience in the context of the vulnerable char (island) people of Bangladesh. Both qualitative and quantitative approaches have been applied to data gathered from hazard-prone char areas. The findings show that due to low education and organizational participation, most of the char dwellers are not aware of their rights, though they are still suffering from a lack of basic public services. The study also reveals that the administrative system of the local char areas is not able to respond to adverse effects of natural disasters due to ignorance, inefficiency, lack of commitment, accountability and corruption. The administrative system of the char areas fails to manage the harmful impact of natural disasters on the social system. This study also finds that administrative resilience is poor in the vulnerable char areas in Bangladesh and that char dwellers are unable to help themselves due to chronic poverty, seasonal unemployment, poor communication networks, and geographical isolation. Context-specific disaster management policies and effective monitoring systems should be developed by the government to improve administrative response in the geographically isolated areas.
\end{abstract}

Keywords: resilience, administration, risk management, governance, environmental management

\section{Introduction}

Resilience is a holistic concept that has gained a popularity nowadays across a range of social science disciplines. It refers to the ability of an individual or

*e-mail: sarker.scu@yahoo.com

system to withstand the shocks and stress of social or natural disturbances $[1,2]$. For social systems, this ability involves a range of critical administrative structures and capacities aimed at reducing uncertainty and increasing the likelihood of effective response [3,4]. With respect to disturbances in socio-ecological systems (i.e., natural disasters), administrative resilience is considered an essential capacity for effective organizational response [5]. Scholars and practitioners of public policy now stress the need for administrative resilience to become 
a key public policy goal for coping with the risks, shocks, and vulnerabilities associated with natural disasters $[6,7]$.

Since the 1980s, the concept of resilience has been used in emergency preparedness and management [8] and natural resource management [9]. Hood (1991) introduced the concept of resilience in the public administration in the 1990s as a neglected concept which conflicted with "efficiency" to the previous administrative interest. But in 2000, resilience gained popularity in public administration to address vulnerability and crisis. As a new domain, administrative resilience was used in governance system to address uncertainty and complexity [10]. Generally, two considerations of administrative systems are related to resilience; first, the level of concept, plan, and preparation of an administrative system to prevent, mitigate and adapt to adversity; second, the level of response to uncertainty and complexity through innovation, learning and adaptation strategies [11, 12]. Administrative resilience promotes people on the object to remain stable during and after adversity.

The administrative system is responsible for solving or reducing the vulnerability that emerges from dynamic and uncertain conditions by developing the capacity of the system [13]. Ostrom and Janssen [14] mentioned that uncertainty increases the odds of making the wrong choice. In this situation, the administrator cannot predict the uncertainty of the system and ultimately fails to achieve the desired outcome. Generally, two things happen in an uncertain situation; first, the administrator cannot predict whether a specific action can bring a specific outcome due to the previous knowledge about the situation, which is highly changeable; second, changing the operational environment, which can modify the processor to modify outcomes [9]. In this situation, administrative resilience can respond to uncertainty, crisis, and risks through minimizing administrative constraints and allowing greater freedom of action [15, 16]. Access to information is a major key by which the administrative system can improve its capacity to deal with uncertainties. According to Kettl [17], a polycentric governance system can handle adversity in an effective way due to the heterogeneous network. It is now established that the network can play a vital role in the public governance system. The multiple skills, ideas and approaches can enhance the administrative capacity to tackle and adapt to the situation by informing decision makers.

The importance of administrative resilience for its robustness, potential, and involvement with the people and society is getting increasing interest by scholars. Particular areas like Bangladesh are more vulnerable to natural disasters, thus public administrators are confronted with various hazardous situations. Organizational preparedness is necessary to control, monitor and adapt to the situation. This study intends to address the research gap by exploring the potential of administrative resilience to improve the livelihood resilience of the people using the vulnerable char (island) context of Bangladesh as a case study.

A riverine island (char) is a place in a riverbed that has developed due to deposition of silt and alluvium [2]. The main characteristics of char areas are extreme geographical isolation. In Bangladesh, there are around 900 chars $\left(7200 \mathrm{~km}^{2}\right)$ that regularly experience riverbank erosion, flooding and other natural disasters. Char dwellers are deprived from almost all basic services such as education, health, electricity, and transportation, which make them more vulnerable [2].

This study also developed a workable framework for a better understanding of the role of administrative resilience for disaster management. The rest of our paper is arranged as follows: section 2 describes the conceptual framework of administrative resilience; section 3 deals with methodology; section 4 deals with results and discussion focusing the status of administrative resilience in the char areas; and the final section concludes the paper.

\section{Conceptual Framework}

In response to disaster risk or disruptive events, the administrative system faces different situations in a heterogeneous way. Haase [9] mentioned few specific factors that are responsible for controlling administrative resilience such as awareness of the risk, and capacity, access to procedures, quick decision making and the ability to act and adapt. An administrative system can take a decision, adapt strategies and organize themselves to manage the disaster context by addressing these factors.

Livelihood resilience focuses on the capacity of a livelihood system to withstand the adverse effects of natural disasters, whereas administrative resilience focuses on the capacity of an administrative system to cope and withstand and recover from the adverse effect of internal or external factors such as corruption, bribery, "red-tapism," risks and threats and natural disasters (Fig. 1). So, a disaster-prone population and its livelihood are under the span of control of an administrative system. The administrative system can improve the livelihood of the disaster-prone people by using their resilience capacities. Most counties have their own disaster management policy for ensuring the better livelihood of vulnerable people through adaptive governance. The resilience strategy for one area is not applicable to other areas because of the changing climate context.

Nowadays policy makers are always considering strategy and the approaches of resilience to policy decisions $[18,19]$. The resilience approach has also been adapted by some international organizations such as the Department of International Development (DFID), Christian aid, CARE and Oxfam [20, 21]. Administrative resilience solves the complexity and uncertainty of an integrally resilient system through ensuring the 


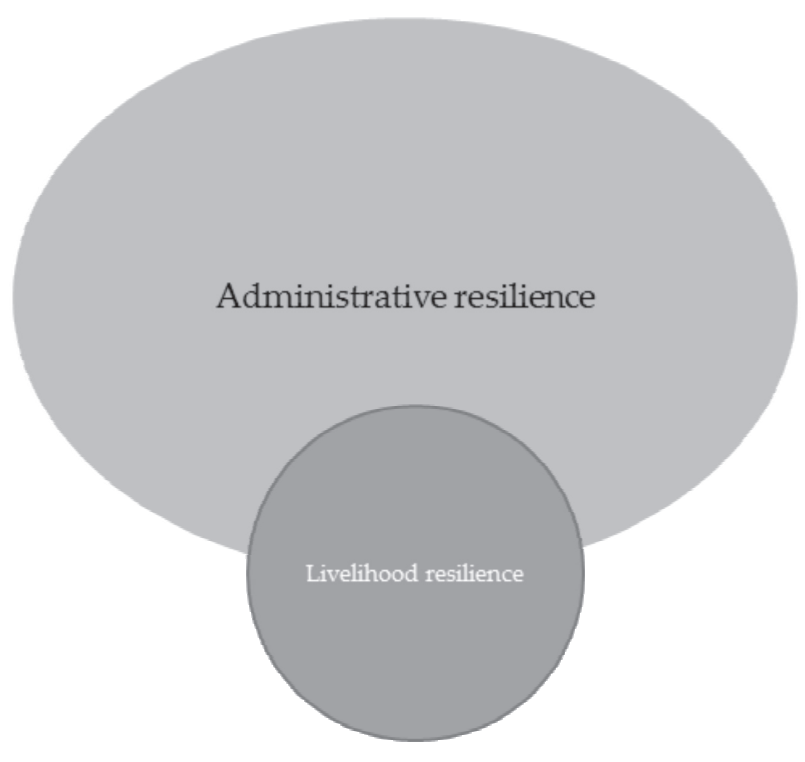

Fig. 1. Relationships between administrative and livelihood resilience.

capacity to learn, self-organization and retaining structure, enabling social network and institution. As a potential tool, administrative resilience acts as an enabler, is reflexive and transforms for recovery to an adverse situation from a detrimental one [22, 23]. Most developing countries have a rigid structure of governance that involves corruption, malpractice, bribery, redtapism, no transparency and little accountability, which enhances vulnerability. Therefore, current institutional status should be understood for incorporation of the administrative resilience approach for enhancing the capacity of the socio-ecological system to disaster risk [20].

As in livelihood resilience, administrative resilience status can be easily found by using three capacities such as adaptive, absorptive, and transformative [2]. According to Alinovi et al. [1], resilience is a combined effect of adaptive, absorptive and transformative capacities. Though sub-indicators of the major component may vary, a composite index using these capacities can determine the exact status of the resilience of a household or community (Fig. 2).

Adaptive capacity is a capability to make desirable choices of alternative strategies of livelihood in the context of dynamic conditions. Factors that contribute to adaptive capacity include bridging and connecting social capital and ambitions as well as the confidence to adapt, livelihood diversity, asset ownership, and human capital. Access to basic services are important factors for developing adaptive capacity. Though the extent of benefits depends on access, availability, time and quality of services, particular basic services can enhance an individual's and community's capacity to withstand the adverse effects of natural disasters [2, 24]. People who have access to information about climate trends and work availability may be able to make better decisions affecting their future and therefore increase their resilience [25]. Absorptive capacity is the capability to reduce exposure to disturbances and recover quickly. Absorptive capacity contributes to resilience through interventions that strengthen disaster risk reduction and

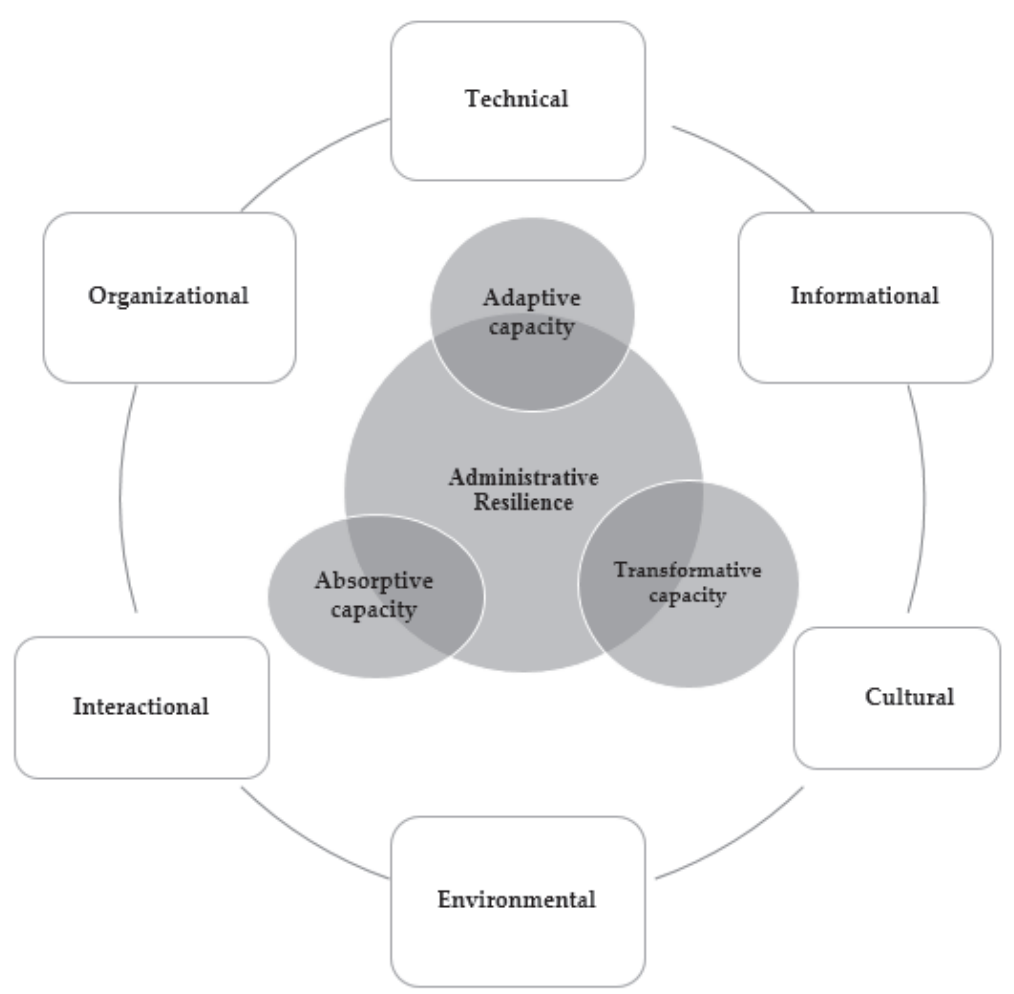

Fig. 2. Major components of resilience in an administrative system. 
response capacity that reduce the loss of lives and assets [26].

Transformative capacity is comprised of system-level enabling conditions such as governance mechanisms of the administrative system, policies, rules and regulations, infrastructure, social networks, and social protection mechanisms that create an enabling atmosphere for systemic change. Other factors include bridging and linking social capital, access to markets and services, and women's empowerment [27]. In addition, Haase [9] mentioned six components of administrative resilience (organizational, cultural, informational, technical, interactional, and environmental component) which are working under two major systems like system structure and system process. The system structure consists of the environment, technological and interactive components, while the system process consists of information, organization, and cultural components.

In this study, the indicators of administrative resilience are developed based on an intensive review of the literature, expert consultation, and field experiences. The indicators used in this study are presented in Table 1.

\section{Methodology}

\section{Research Design}

This study was based on qualitative methods, particularly a case study conducted in geographically isolated riverine char areas in Bangladesh. The case

Table 1. Administrative resilience components and expected relationships.

\begin{tabular}{|c|c|c|}
\hline Major dimensions & Sub-components & Expected relationship \\
\hline \multirow{8}{*}{$\begin{array}{l}\text { Adaptive } \\
\text { capacity }\end{array}$} & Disaster management training to people & $\begin{array}{l}\text { Disaster management training increases the adaptive capacity of } \\
\text { people. }\end{array}$ \\
\hline & Encouraging local level leadership & Local leadership helps to increase administrative resilience. \\
\hline & Forming a community level organization & $\begin{array}{c}\text { Community-based organization enhances awareness of the people } \\
\text { which ultimately increase resilience. }\end{array}$ \\
\hline & Early warning system & $\begin{array}{l}\text { Early warning system helps people to avoid any undesirable situ- } \\
\text { ation and increase resilience. }\end{array}$ \\
\hline & Building disaster shelter & $\begin{array}{c}\text { Disaster shelter helps people to take shelter during a disaster and } \\
\text { ultimately increases resilience. }\end{array}$ \\
\hline & Training for agricultural practices & $\begin{array}{l}\text { Agricultural practices training helps to get more production and } \\
\text { ultimately increases resilience. }\end{array}$ \\
\hline & Income generating activities training & Income generating activities during disaster increase resilience. \\
\hline & Health-related training & Training on health helps to increase resilience. \\
\hline \multirow{5}{*}{$\begin{array}{l}\text { Absorptive } \\
\text { capacity }\end{array}$} & Minimization of failure & Failure of disaster management project reduces resilience. \\
\hline & Early detection & $\begin{array}{c}\text { Early detection of any weakness of disaster projects helps to solve } \\
\text { it and increases resilience. }\end{array}$ \\
\hline & Bureaucratic flexibility & $\begin{array}{c}\text { The flexibility of any administrative initiative helps to absorb any } \\
\text { undesirable situation which increases resilience. }\end{array}$ \\
\hline & Bureaucratic controllability & $\begin{array}{l}\text { Strict control of the disaster management policy and monitoring } \\
\text { helps to increase resilience. }\end{array}$ \\
\hline & Reducing the adverse effect & The adverse effect of disaster reduces resilience. \\
\hline \multirow{7}{*}{$\begin{array}{l}\text { Transformative } \\
\text { capacity }\end{array}$} & Immediate action during a disaster & Immediate action at the time of disaster increases resilience. \\
\hline & Relief during and after the disaster & Relief distribution increases resilience. \\
\hline & Cash incentives & Cash incentives increase resilience. \\
\hline & $\begin{array}{l}\text { Evacuation of people from the place of } \\
\text { disaster }\end{array}$ & $\begin{array}{l}\text { Evacuation of people from disaster areas helps to increase resil- } \\
\text { ience. }\end{array}$ \\
\hline & $\begin{array}{l}\begin{array}{l}\text { Ensuring public services during and after the } \\
\text { disaster }\end{array} \\
\end{array}$ & Public services during and after the disaster increase resilience. \\
\hline & $\begin{array}{c}\text { Controlling corruption in project implementa- } \\
\text { tion }\end{array}$ & $\begin{array}{c}\text { Controlling corruption in project implementation increases } \\
\text { resilience. }\end{array}$ \\
\hline & $\begin{array}{l}\text { Engaging special task force for disaster } \\
\text { management. }\end{array}$ & The action of the special task force increases resilience. \\
\hline
\end{tabular}

Source: Based on a literature review, expert consultation, and key informants. 
study consisted of face-to-face interviews, focus group discussions (FGDs), key informant interviews (KIIs), and life history for obtaining in-depth insights of administrative resilience in the study areas. A faceto-face interview with household heads and semistructured questionnaire for FGDs and KIIs were also conducted. One FGD consisting of 10-12 household heads was conducted in every village in order to get opinions regarding administrative resilience. Moreover, a life history interview on 34 char dwellers taking two respondents from each village was conducted for obtaining in-depth information about the trend of natural disasters, adaptation capacities and responses of the local administration.

\section{Measuring Administrative Resilience}

The study followed the approach developed by Alinovi [1] for measuring administrative resilience. The indicators used in this study were developed through an extensive literature review, expert consultation, and key informant interviews. The indicators focused on the local context of the administrative, social and ecological systems of the study areas:

\section{Administrative resilience $=f$ (adaptive, absorptive and transformative capacity)}

These capacities provide a valid ground of resilience measurement. Besides, the study also followed the approach developed by Haase [9], according to whom administrative resilience is a function of six major components: environment, technology, interaction, information, organization and cultural components. All the components were considered and evaluated under a local context basis. The evaluation of the components of administrative resilience focused on the status of the administrative system for responding to natural disasters. This study develops a four-point scale ranging from zero to three, indicating no, low, medium and high levels of administrative intervention in the face of disasters. No level means almost no intervention paid by the local administration, while low means 1 to 2 times per six months, medium means 3 to 5 times and high means frequently when necessary. This study summarized the data obtained by multiple focus group discussions and took averages of them for meaningful presentation of administrative intervention. This kind of scale is frequently used by some other researchers for measuring the extent of extension agent visits in rural areas [28-30].

\section{Site Selection and Geographical Features}

A case study approach has been applied to the vulnerable geographically isolated char areas of Saghata and Fulchhari upazila in Gaibandha District of Bangladesh. The main characteristic of char areas is geographical isolation. Chars belong to all the big rivers in Bangladesh. As a top widest river, Jamuna has more chars than other rivers. It occupies $45 \%$ of the char areas of the country. Char of the Jamuna is a place of $65 \%$ of the total char dwellers [31]. A number of chars emerge in the Jamuna over time, with some chars being relatively new and some old. Char dwellers prefer to live in old settled char due to relatively low risk and opportunities for crop cultivation. Some chars are near the mainland and some are distant from the mainland. Char dwellers are more dependent on agriculture since the opportunity for other professions is relatively low and, in some cases, rare. Char dwellers are vulnerable to social, ecological and administrative perspectives due to limited access to social capital, natural resources, education, health, and basic public services [32, 33]. They are the deprived community in Bangladesh. Therefore, this study has selected seventeen char villages of the Jamuna under two local administrative units (upazila) that represent almost all other char areas in Bangladesh (Fig. 2). The study villages under Saghata Upazila were Haldia, Patilbari, Garamara, Digalkandi, Guabari, Kanaipara, Kalurpara, Kumarpara and Hatbari. The distant island villages under Fulchhari Upazila were Deluabari, Jamira, Bajefulchhari, Kholabari, Pipulia, Tenrakandi, Gabgasi and Baghbari.

\section{Data Collection}

The study used a questionnaire survey and focus group discussions (FGDs) for the collection of data regarding livelihood assets, socio-demographic profiles and vulnerability indicators and adaptation strategies. The sample size was determined by the following formula developed by Yamane [34]: the total population in the study area was 5666 and the sample size was determined by applying the Yamane [34] method of sample size determination, therefore the sample size was 374 for this study. Simple random sampling technique was done for selecting household head in the char villages. A structured questionnaire has been developed comprising open and close-ended questions. The questionnaire was prepared based on literature review and expert consultation to meet the objectives of the study. The questionnaire survey and FGDs for this study were conducted from January to August 2017. Prior oral consent was taken from the household head before the interview. Face-to-face interviews, however, were a better way to make rapport and get in-depth information.

\section{Results and Discussion}

The findings of this study are presented in three parts; the first section highlights char dwellers access to basic services, which presents the government's intervention to ensure basic services at rural char villages' level; the second section presents the status of administrative resilience in the char areas; and the 


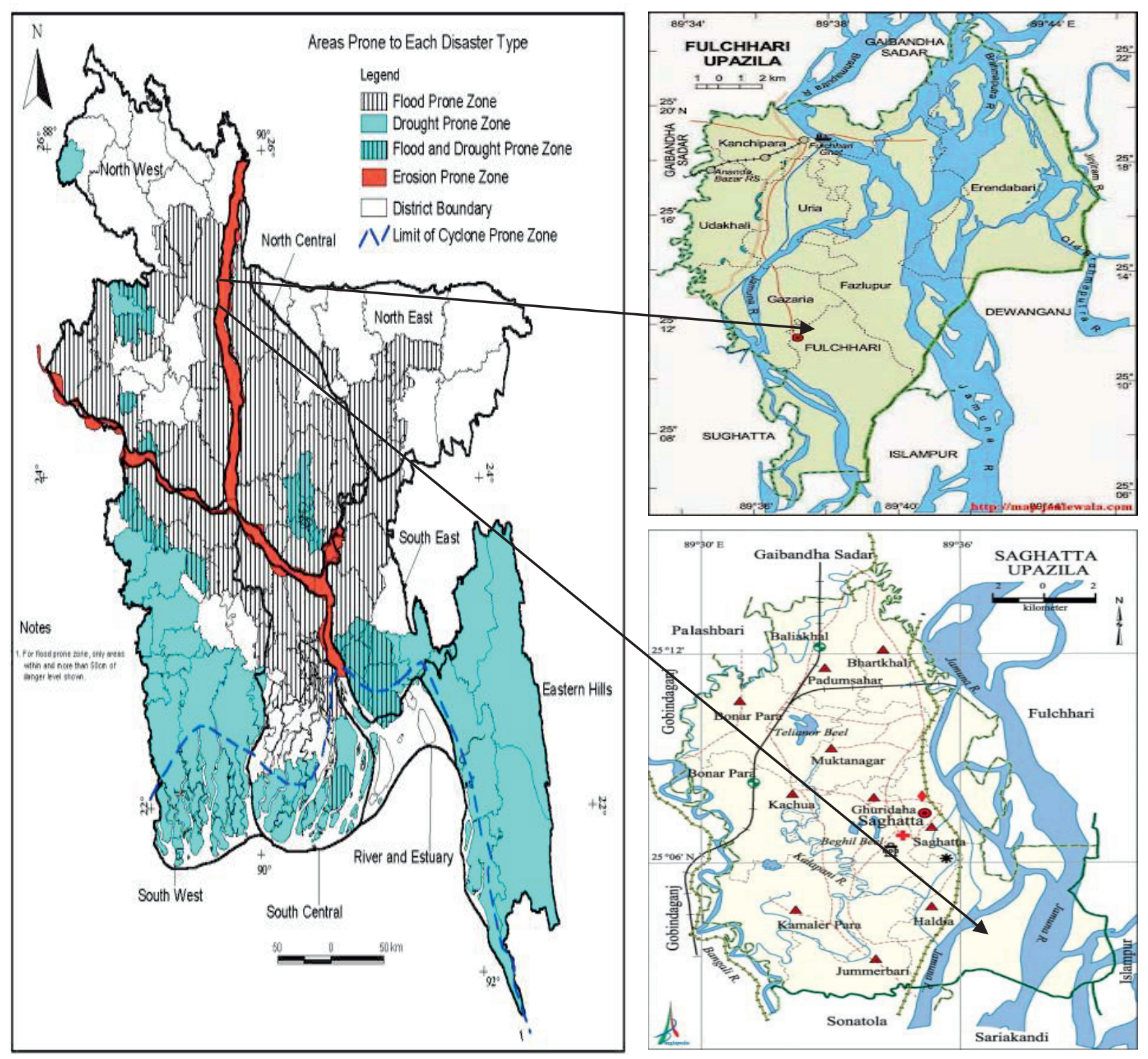

Fig. 3. Study areas (Saghata and Fulchhari upazila) in Bangladesh (source: http://ontheworldmap.com/bangladesh/large-detailed-mapof-bangladesh-with-cities.html).

third section focuses on component-wise administrative resilience and opinions of the char dwellers.

\section{Access to Basic Services}

Char dweller's access to basic services has been assessed in terms of access to education, health extension contacts, khas land ${ }^{1}$, credit, social safety nets, organizational participation, training and information and communication technology (ICT). In this study

Khas land means newly accreted land owned by the government. In char areas, riverbank erosion and emerging new lands are regular phenomena. Every year some new chars emerge in river beds where nobody has property rights and are considered government fallow or khas land. we found that about $40.91 \%$ char dwellers are illiterate while only $39.84 \%$ within a primary level and only $1.87 \%$ have completed higher secondary level. It is very much lower than the national literacy rate $(72.76 \%)$. The status of access to the health of char dwellers shows that only $16.58 \%$ have taken treatment from a qualified doctor (professional medical degree holder) and the rest of them take treatments from a local doctor (only 3/6 months medical training holder) and medicinal plant sellers (Table 2).

We also found that about $11.76 \%$ of households have at least one chronic illness. In the perspective of a char dweller's extension contact, it is revealed that only $21.66 \%$ have high contact with extension agents such as agricultural extension agent, health workers, NGO workers, experienced farmers, agricultural input traders, 
Table 2. Access to basic services of households.

\begin{tabular}{|c|c|c|c|}
\hline \multirow{2}{*}{ Major services } & \multirow{2}{*}{ Indicators } & \multicolumn{2}{|c|}{ Response } \\
\hline & & No. of respondent & Percentage \\
\hline \multirow{5}{*}{$\begin{array}{l}\text { Level of educa- } \\
\text { tion }\end{array}$} & Illiterate $(0)$ & 153 & 40.91 \\
\hline & Primary (level 1-5) & 149 & 39.84 \\
\hline & Secondary (level 6-10) & 52 & 13.90 \\
\hline & Higher Secondary (level 11-12) & 13 & 3.48 \\
\hline & Above higher Secondary $(>12)$ & 7 & 1.87 \\
\hline \multirow{5}{*}{ Status of health } & Generally taken treatment from a qualified doctor & 62 & 16.58 \\
\hline & Family members having chronic ill & 44 & 11.76 \\
\hline & Taken treatment from a local doctor during illness & 305 & 81.55 \\
\hline & Having sanitary latrine & 142 & 37.97 \\
\hline & Family member missed work or school due to illness in the past two weeks & 63 & 16.84 \\
\hline \multirow{3}{*}{$\begin{array}{l}\text { Extent of } \\
\text { extension } \\
\text { contact }\end{array}$} & Low contact & 157 & 41.98 \\
\hline & Medium contact & 136 & 36.36 \\
\hline & High contact & 81 & 21.66 \\
\hline \multirow{3}{*}{$\begin{array}{l}\text { Access to khas } \\
\text { land }\end{array}$} & Received khas land & 25 & 6.68 \\
\hline & Applied for khas land & 13 & 3.48 \\
\hline & Don't know the procedure about khas land & 108 & 28.88 \\
\hline \multirow{2}{*}{ Access to Credit } & NGOs & 43 & 11.50 \\
\hline & Commercial bank & 17 & 4.55 \\
\hline \multirow{8}{*}{$\begin{array}{l}\text { Access to Social } \\
\text { Safety Nets } \\
(\mathrm{SSN})\end{array}$} & Member of NGO's SSN program & 81 & 21.66 \\
\hline & Getting skill development training from NGO & 89 & 23.80 \\
\hline & Getting any financial help from NGO & 102 & 27.27 \\
\hline & Receiving any relief from NGO during a disaster & 184 & 49.20 \\
\hline & Member of GO's SSN program & 35 & 9.36 \\
\hline & Getting skill development training from GO & 22 & 5.88 \\
\hline & Getting any financial help from GO & 45 & 12.03 \\
\hline & Receiving any relief from GO during a disaster & 145 & 38.77 \\
\hline \multirow{2}{*}{$\begin{array}{l}\text { Participation } \\
\text { and training }\end{array}$} & Organizational participation & 114 & 30.48 \\
\hline & Training received & 107 & 28.61 \\
\hline Access to ICT & Mobile usages & 162 & 43.32 \\
\hline
\end{tabular}

Source: Field survey, 2017

and local traders. In regards to khas land, only $6.68 \%$ of char dwellers have access to khas land, while some of them (3.48\%) applied for khas land with the help of NGOs and the rest of them do not know about khas land rights and the procedure for obtaining it.

Considering access to credit, it is revealed that only $11.5 \%$ of char dwellers have access to NGO credit programs, while only $4.55 \%$ have access to a commercial bank. This is due to the unwillingness of banks, NGOs and other microfinance instruments to work in char areas. In regards to safety net programs, only $11.5 \%$ of char dwellers are members of NGO programs, whereas only $9.36 \%$ are GO members. Only $5.88 \%$ of char dwellers get GO skill development training, while $23.8 \%$ get NGO training. Similarly, $12.03 \%$ get financial help and $38.77 \%$ receive relief from GOs, and $27.27 \%$ and $49.2 \%$ from NGOs.

In the perspective of organizational participation and training, only $30.48 \%$ and $28.61 \%$ of char dwellers are a participant and get training from organizations respectively. We found that only $43.32 \%$ of char dwellers use a mobile phone for communicating 
Table 3. Administrative resilience status in char areas.

\begin{tabular}{|c|c|c|c|c|c|}
\hline \multirow{2}{*}{ Major dimensions } & \multirow{2}{*}{ Sub-components } & \multicolumn{4}{|c|}{ Extent of intervention } \\
\hline & & No & Low & Moderate & High \\
\hline \multirow{8}{*}{ Adaptive capacity } & Disaster management training to people & & $\sqrt{ }$ & & \\
\hline & Encouraging local level leadership & & $\sqrt{ }$ & & \\
\hline & Forming a community level organization & & $\sqrt{ }$ & & \\
\hline & Early warning system & & $\sqrt{ }$ & & \\
\hline & Building disaster shelter & & & $\sqrt{ }$ & \\
\hline & Training for agricultural practices & & $\sqrt{ }$ & & \\
\hline & Income generating activities training & & & $\sqrt{ }$ & \\
\hline & Health-related training & & $\sqrt{ }$ & & \\
\hline \multirow{5}{*}{ Absorptive capacity } & Minimization of failure & & $\sqrt{ }$ & & \\
\hline & Early detection & $\sqrt{ }$ & & & \\
\hline & Flexibility & $\sqrt{ }$ & & & \\
\hline & Controllability & & $\sqrt{ }$ & & \\
\hline & Reducing the adverse effect & $\sqrt{ }$ & & & \\
\hline \multirow{7}{*}{$\begin{array}{l}\text { Transformative } \\
\text { capacity }\end{array}$} & Immediate action during a disaster & & $\sqrt{ }$ & & \\
\hline & Relief during and after the disaster & & $\sqrt{ }$ & & \\
\hline & Cash incentives & & & & \\
\hline & Evacuation of people from the place of disaster & & $\sqrt{ }$ & & \\
\hline & Ensuring public services during and after the disaster & & $\sqrt{ }$ & & \\
\hline & Controlling corruption in project implementation & & $\sqrt{ }$ & & \\
\hline & Engaging special task force for disaster management. & $\sqrt{ }$ & & & \\
\hline
\end{tabular}

Source: Based on focus group discussions, 2017

with others. Government can provide useful information of agriculture and disaster preparedness issues through mobile phones [2]. Considering the above issues, it is found that char dwellers have a poor level of access to public services, which increase their vulnerability.

\section{Administrative Resilience in the Char Areas}

The status of administrative resilience in the char areas is obtained by assessing opinion of the char dwellers regarding government administrative interventions. This study explores that most char dwellers received no training on disaster management. But people can increase their adaptive capacity by getting knowledge and skill from training on disaster management. We have found that most char villages have no farmers' organization, a major cause of weak social network and local leadership. Most of the char dwellers mention that few disaster shelters are available to accommodate all the victims of disasters. Similarly, a majority of the char dwellers opine that they did not get any early warning message of disasters, or training on agricultural practices, health, and income- generating activities. According to most char dwellers, the patterns of government and private organization development initiatives have failed to achieve the desired outcome or absorptive capacity. The overall status of administrative resilience in the char areas is presented in Table 3.

Char dwellers also mention that local administrative immediate response during disaster relief distribution, especially food and daily necessary items, cash incentives, and evacuation, are low level and characterized by corruption. Proper initiative and monitoring can improve the response of local administrative systems and enhance char dwellers transformative resilience.

\section{Adaptive Capacity}

Adaptive capacity is the ability of an administrative system to cope with the stress and shocks of natural hazards, and to protect citizens from the harmful effect of natural disasters. Since char areas are highly vulnerable to climate variability and natural disasters, enhancement of the adaptive capacity of the rural institution is a priority. 
Char areas are neglected in terms of administrative intervention due to geographical isolation, no communication network and the unwillingness of the administrators. I did not get any training from any organization, so it is difficult for me to take any adaptive action against the adverse effect of disasters. (Interviewee\# 5)

According to Duit [13], the institution has influence to enhance the adaptive capacity of rural people by transforming a coping strategy to adaptive capacity. This study reveals that the adaptive capacity of the local government institution in the char areas is unable to manage the situations of natural disasters [35].

There is almost no leader in char areas to help others to take any cumulative action against any disaster event. We have only one local elected representative who is responsible for three villages, and he has a permanent residence in the mainland. So, he is active only at the time of the Union Parishad [the lowest administrative unit at village level] election but he has no initiative to save char areas at other times. So, we are almost deprived of active leadership. (Interviewee\# 12)

The study explores ways for enhancing adaptive capacities such as disaster management, local level leadership and community-level organization, early warning systems, disaster shelters, agriculture, incomegenerating activities, and health-related training [4].

Only a few literate people get training from government and non-government organizations, but most of the char dwellers did not get any training related to disaster management and agricultural practices like me. If we get training from any organization, it will help us to survive. (Interviewee\# 123)

\section{Absorptive Capacity}

Absorptive capacity is the ability of an administrative system to take additional responsibility in the face of sudden uncertainty, shocks, risks and natural hazards. According to Adger et al. [36], absorptive capacity minimizes peoples' susceptibility to natural hazards. This study reveals that the absorptive capacity of the administrative system is very poor and unable to tackle the situation during disasters. If the absorptive capacity of char dwellers is poor, it means that they are not capable of managing the adverse situation. Since the administrative system of the study area deals with socially vulnerable people, absorptive capacity of char dwellers should be developed along with that of the administrative system.

As like me, most of the char dwellers have a low or no ability to withstand the harmful effect of disasters. According to my knowledge, most of the char development projects did not accept local strategies and ignore local people, which seems a major reason for the little outcome and poor development. (Interviewee\# 364)

I am 50 years old. I saw a number of the projects in the char villages for developing the livelihood of char dwellers, but most of them temporarily help char dwellers. As a result, char dwellers faced the same problems after completion of the project. (Interviewee\# 115).

Most of the char projects followed the topdown approach so it was not appropriate to the context of char areas. So, probably it failed to draw the actual problems of the char areas. It was because of a low idea of the policy makers about the challenges of the char area and corruption at different levels in the implementation phase. (Interviewee\# 261)

Analyzing the statements of the char dwellers, we found that intervention from government and nongovernment organizations were launched several times for improvement of the livelihood conditions of the char dwellers. But due to lack of char-oriented strategy, ignoring local people and adaptation strategies, the intervention failed several times. It was also found that there was little collaboration among the organizations working in the char areas. Char dwellers argue that there was poor monitoring and supervision paid for by the local and state level administrators in the implemented project.

The study has identified five sub-indicators of absorptive capacity of the local administrative system in the study areas, such as minimization of failure, early detection, flexibility, controllability, and reducing the adverse effect.

Char dwellers are a resource-poor farmer like me. Most of them are not capable of managing the shock of natural disasters. So, we are seeking training from government agencies about the necessary means to save ourselves.

(Interviewee\# 167)

\section{Transformative Capacity}

Transformative capacity is the ability of an administrative system to convert the policy to action for the protection of the people and society from uncertain environments. Transformative capacity is a key element for protecting people from natural disasters [13]. The administrative system is always transforming the rules, regulations, policy, and plan into action for implementing the strategy at field level for protecting people and society [8]. The study reveals that the transformative capacity of the administrative system is not satisfactory to save the people and their livelihood. This study also explores some indicators of adaptive capacity so that an administrator can apply it at field level for protecting people and nature. The major required initiatives for disaster management in char areas are relief distribution, cash incentives, evacuation initiative, emergency public 
services, controlling corruption, and special intervention for disaster management.

I am 53 years old and living in Bajefulchhari Village. I was born in another char village but due to riverbank erosion and recurrent flood, we have lost our lands, houses, and other assets. We are seeking immediate action from public agencies during and after disasters. In the previous disaster, we didn't get proper initiatives from the local administration. (Interviewee\# 82)

I have a large family consisting of seven members. We are only two earning members. We can earn during agricultural harvest seasons. But we face very much difficulty during flooding, when we have no work and we are unable to buy food and daily necessities. In that situation, we needed food and we were waiting for relief distribution from GOs and NGOs. So, we were seeking a government organization's relief during and after disasters. (Interviewee\# 19)

According to the opinion of the char dwellers, we found that the extent of intervention from the local administration is not enough to develop the capacity of the people against the detrimental effect of natural disasters. Seasonal unemployment, riverbank erosion and recurrent flooding are the major causes of seasonal food insecurity and poor transformative capacity.

I am 47 years old and living in Patilbari Village. In the last flood I lost my land, houses and other assets. Now I am a resource-poor day laborer. I did not get any help from any agency. As a victim, I am seeking a cash incentive for building a small house to save my family members. (Interviewee\# 107)

I have been living in Tengrakandi Village for the last 12 years. Before that time, I was living in Khatiamari Village. In my 38 years of life, I have never seen any evacuation initiative of any institution during disasters. Char dwellers are helpless and hopeless in the event of disasters. We are seeking help from government organizations for launching an evacuation system for char dwellers during disasters. (Interviewee\# 119)

Char dwellers argue that they moved several times due to recurrent disasters. Every disaster causes a huge loss of livelihood assets that results in char dwellers being forced to migrate from one char to another. It is also known that the evacuation facility of the local government is not enough to deal with thousands of char dwellers. It shows the inability of the administrative system to take proper initiative during disasters.

I am 43 years old and live in Zamira Village. I saw a few disaster shelters in some villages in Saghata and Fulchhari upazila. But we have no disaster shelter. We have to move the dam adjacent to the mainland for saving ourselves from flooding. If we get any disaster shelter in our village, we can save ourselves and our property from flooding. (Interviewee\# 212)
Char dwellers also argue that disaster shelter is a main place for saving people and movable assets during disasters, but due to lack of it, most of the char dwellers are bound to move to the mainland. This shows the severity of the calamity of char dwellers during disasters as well as the local administration's inability to take proper action. Establishing more disaster shelters and instant cash incentives can solve the problems and reduce the vulnerability of the char dwellers.

\section{Component-Wise Status of Administrative Resilience in the Char Areas}

The six major components of administrative resilience are: environmental, technological, interactive, and information, organizational and cultural components. The opinions of the char dwellers from life history are presented according to the components of administrative resilience.

\section{Environmental Component}

The administrative system is responsible for developing, implementing and monitoring rules, regulations, and policy of disaster management. It is also responsible for caring for the people who are supposed to be a victim of natural disasters. It works to mitigate the causes of climate change and make a strategy for better adaptation. Environmental components of the administrative system also emphasize planning, policy and awareness of the system focusing on environmentrelated issues. The major sub-components are social and governmental awareness, rules, regulations, and plans for disaster management and institution [9].

So far, I know, the government has a priority of climate change and disaster management issues. But char areas are neglected due to unknown reasons. I think the major reasons for improper implementations are lack of local administrative leadership, monitoring, ignorance of local representatives, lack of education and awareness of char dwellers and huge corruption during project implementation. (Interviewee\# 33)

\section{Technological Component}

Technology is a key tool for tackling a risky operational environment. The main focus of the technological component is to address technological suitability in order to apply effective operations. Technological components can enhance the adaptive and transformative capacity of the administrative system. It basically focuses on weather forecasting, disaster forecasting, early warning, and evacuation. Technological integration is a basic task of the administrative system for effective adaptive governance, especially during a disaster-prone period. The major sub-components are availability and adaptability of technology, interoperability, form, integration, and 
interoperability of technology in an administrative system [37].

Most of the char household heads use mobile phones, they use it only for communicating with others. Other technological use is almost absent. We don't get an early warning of disasters, no forecasting of flooding and no initiative for evacuation. We are seeking kind intervention from the government regarding forecasting, warning and evacuation messages from the local administration. (Interviewee\# 197)

\section{Interaction Component}

The interaction component focuses on the ability of one administrative system to interact with others, such as other public organizations, private organizations, voluntary organizations, donor organizations, and international organizations. This component is very much responsible for exchanging information, experiences, knowledge, resources, and experts to handle the situation of disasters. It works before, during and after disasters to minimize the losses. The major sub-components of the information component are resources, personnel, information, expert and evolution [21].

I am 57 years old and living in Pipulia Village. I lived in this village in my childhood. I have migrated several times from one place to another due to riverbank erosion. I have lost my land and other properties due to flooding and riverbank erosion. I have seen many projects implemented by GOs and NGOs but their effectiveness was very poor in that most of the projects were low-lasting. I think that the major reasons are excluding the local people and adaptation strategies from project design to implementation. I think local interaction is necessary for getting proper results. (Interviewee\# 315)

\section{Information Component}

A proper and accurate decision requires authentic information, which is an important component of the administrative system. It helps to know the exact situation of the disaster, organizational ability, and possible intervention. Without information, no one can design, implement or monitor the governance system. So the availability of information is better for the governance system to manage adverse events. The major sub-components of information components are the availability, value, quality, authenticity, and acceptance of information [9].

I have been living in Char Deluabari Village since my childhood. I have seen that char dwellers are deprived of accurate and necessary information regarding disasters, markets, agriculture, and healthcare. We only get weatherrelated information from news broadcasted by the radio program from the capital city. But central weather forecasting is less effective in the char areas of the northern part of the country. We hope that the government will take an effective measure regarding proper information dissemination through establishing a char-based weather forecasting office and community radio centers. (Interviewee\# 261)

\section{Organizational Component}

The organizational component focuses on how to address the problem of a disaster context in an effective way. It helps to organize the related stakeholders to make a good and rapid solution for managing the risk immediately. Rapidity and adjustment are the major characteristics of the organizational component, which help to solve the problem rapidly and adjust the situation as the previous one. Organizational component mainly emphasize increasing the adaptive capacity of the administrative system by providing training, knowledge dissemination, planning, organizing, budgeting, and coordinating related stakeholders. It also focuses on the maximum utilization of resources for disaster management. The major sub-components of the organizational components are the plan of work, authority, expert personnel, training, resource management and flexibility [4].

I am 38 years old and living in Kumarpara Village. I am a participant of a local NGO and get training related to agriculture. I have seen that there is a lack of coordination between NGOs and GOs working in the char areas for development. This lack of coordination makes the repetition of the same work in different areas of the same village. So, rapid development requires proper organization and coordination of works of various institutions for char areas. (Interviewee\# 317)

\section{Cultural Component}

The cultural component address how the administration can identify the similarities and differences between the present problem and previously faced problems for developing an effective strategy. This component emphasizes pattern-matching for solving any unique or unexpected situations raised due to natural disasters. It also considers the local adaptation strategy for disaster management. It gives the importance of organizational awareness, previous experiences, the culture of the community, new approaches and trust [38].

I am 48 years old and an ex-NGO worker living in Kumarpara Village. I have worked for char areas for the last two decades. I have seen that implementation procedures of most of the projects are not compatible with the culture of char areas. This is due to ignoring the previous 
experience of the other projects and causes poor results. We hope the concerned authorities will consider local culture, adaptation strategies, previous experiences and local participation for rapid development of char areas.

(Interviewee\# 118)

\section{Conclusions}

Administrative resilience in the vulnerable char areas is a key tool for reducing livelihood vulnerability and promoting resilience. Char dweller's access to basic services has been assessed in terms of education, health extension contacts, khas land, credit, social safety nets, organizational participation, training, and information communication technology. We found that most of the char dwellers have low access to education, health facilities, extension contact, khas land, credit, and social safety net programs. Char dwellers also have a low level of organizational participation and training. The study also reveals that the administrative resilience of char dwellers is very poor due to administrative unwillingness, ignoring char areas, corruption in project implementation, and failure to consider local input and adaptation strategies. The various capacities of the administrative system are also poor due to ignoring disaster management policies, and related laws and regulations, limiting char dweller participation in decision making, low resources, lack of expertise, lack of information and geographical isolation. Though geographical isolation, transportation, flooding and riverbank erosion are the main difficulties in the char areas, there is a potential for agricultural production and promoting resilience if government provides the basic services through strengthening local public agencies. Administrative resilience in the char areas can be enhanced through developing a disaster informationbased database to support quick decision making, strengthened policies, accountability, and transparency of the administrative unit. Streamlined and more transparent organizational actions are necessary for enabling a warning system and physical structure of the community, promoting international collaboration for gaining experiences from successful events and disaster management funding. The study explores some key indicators of administrative resilience that will be helpful for measuring any adverse effect and conditions related to socio-ecological vulnerability.

\section{Acknowledgements}

This article is funded by the Sichuan University Innovation Spark Project (No. 2018hhs-21), the Management Science and National Governance Disciplines Platform of Sichuan University, and Sichuan University Central University Basic Scientific Research Project (No. skqx201501).

\section{Conflict of Interest}

The authors declare no conflict of interest.

\section{References}

1. ALINOVI L., MANE E., ROMANO D. Measuring Household Resilience to Food Insecurity: Application to Palestinian Households. in Agricultural Survey Methods 341, 2010.

2. ALAM G.M.M., ALAM K., MUSHTAQ S., FILHO W.L. How do climate change and associated hazards impact on the resilience of riparian rural communities in Bangladesh? Policy implications for livelihood development. Environ. Sci. Policy 84, 7, 2018.

3. COMFORT L.K., SUNGU Y., JOHNSON D., DUNN M. Complex Systems in Crisis: Anticipation and Resilience in Dynamic Environments. J. Contingencies Cris. Manag. 9, 144, 2001.

4. TOONEN T. Resilience in Public Administration: The Work of Elinor and Vincent Ostrom from a Public Administration Perspective. Public Adm. Rev. 70, 193, 2010.

5. YANG Y., NIU G., TANG D., ZHU M. Spatial Econometric Analysis of the Effect of Government Governance on Regional Emission Reduction: Evidence from China. Polish J. Environ. Stud. 27, 2833, 2018.

6. HU M., ZHANG J., HUANG J. Assessing SocialEcological System Resilience in Mainland China. Polish J. Environ. Stud. 27, 1085, 2018.

7. ALEKSANYAN A., KHUDAVERDYAN S., VASEASHTA A. Modeling River Ecosystem Vulnerability Assessments Due to Climate Change: Case Study of Armenia. Polish J. Environ. Stud. 24, 871, 2015.

8. BAKER D., REFSGAARD K. Institutional development and scale matching in disaster response management. Ecol. Econ. 63, 331, 2007.

9. HAASE T. W. Administrative resilience: Evaluating the adaptive capacity of administrative systems that operate in dynamic and uncertain conditions. $\mathrm{PhD}$ Dissertation, University of Pittsburg, Pennsylvania, United States, 2009.

10. VANDENABEELE W. Toward a public administration theory of public service motivation. Public Manag. Rev. 9, $545,2007$.

11. NENKOVIC-RIZNIC M., RISTIC V., MILIJIC S., MAKSIN M. Integration of Strategic Environmental Assessment and Environmental Social Impact Assessment into Strategic Territorial Planning: Lessons Learned from Two Cases of Tourism Destinations In Protected Areas. Polish J. Environ. Stud. 25, 1353, 2016.

12. HUSSAIN N. et al. Climate Change Variability Trends and Implications for Freshwater Resources in Pakistan's Eastern Hindu Kush Region. Polish J. Environ. Stud. 27, 665, 2018.

13. DUIT A. Resilience thinking: Lessons for public administration. Public Adm. 94, 364, 2016.

14. OSTROM E., JANSSEN M.A. Multi-Level Governance and Resilience of Social-Ecological Systems. in Globalisation, Poverty and Conflict 239, Kluwer Academic Publishers, 2005.

15. DRAGIĆEVIĆ S. et al. Vulnerability of national parks to natural hazards in the Serbian Danube region. Polish J. Environ. Stud. 22, 1053, 2013. 
16. XU G., KANG M., METZGER M., JIANG Y. Vulnerability of the Human-Environment System in Arid Regions: The Case of Xilingol Grassland in Northern China. Polish J. Environ. Stud. 23, 1773, 2014.

17. KETTL D.F. Governing by Network: The New Shape of the Public Sector. 2004. doi:10.1139/106-157

18. WALKER B., SALT D. Practicing Resilience in Different Ways. in Resilience Practice (eds. Walker, B. \& Salt, D.) 145 (Island Press/Center for Resource Economics), 2012.

19. VAN WELL L. et al. Resilience to natural hazards: An analysis of territorial governance in the Nordic countries. Int. J. Disaster Risk Reduct. 31, 1283, 2018.

20. DJALANTE R., HOLLEY C., THOMALLA F. Adaptive governance and managing resilience to natural hazards. Int. J. Disaster Risk Sci. 2, 1, 2011.

21. HEGGER D.L.T., DRIESSEN P.P.J., BAKKER M.H.N. Evaluations of flood risk governance in terms of resilience, efficiency and legitimacy. Flood Risk Manag. Strateg. Gov. 55, 2018.

22. FOLKE C. Resilience: The emergence of a perspective for social-ecological systems analyses. Glob. Environ. Chang. 16, 253, 2006.

23. MALLICK B., ETZOLD B. Environment,Migration and Adaptation: Evidence and Politics of Climate Change in Bangladesh. 2015.

24. SARKER M.N.I., WU M., ALAM G.M., SHOUSE R.C. Livelihood Vulnerability of Riverine-Island Dwellers in the Face of Natural Disasters in Bangladesh. Sustainability, 11, 1623, 2019.

25. BHUIYAN M.A. H., ISLAM S.M.D.U., AZAM G. Exploring impacts and livelihood vulnerability of riverbank erosion hazard among rural household along the river Padma of Bangladesh. Environ. Syst. Res. 6, 25, 2017.

26. ALFANI F., DABALEN A., FISKER P., MOLINI V. Can we measure Resilience? A proposed method and Evidence from Countries in the Sahel. World Bank: Policy Research Working Paper, The World Bank, 2014.
27. FAO. Analysing Resilience for Better Targeting and Action. 2016. doi:10.11975/j.issn.1002-6819.2015.24.025

28. OLORUNTOBA A., ADEGBITE D.A. Improving Agricultural Extension Services through University Outreach Initiatives: A Case of Farmers in Model Villages in Ogun State, Nigeria. J. Agric. Educ. 12, 273, 2007.

29. UGWUOKE B.C.. ATTAMAH C.O. Linkages between the Agricultural Development Programme and the Local Government Agricultural Department in Southeast, Nigeria. J. Agric. Ext. 23, 130, 2017.

30. NWABUGWU T.S., NWOBODO C.E.. OKORO J.C. Awareness and Use of E-Resources Among Public Extension Personnel in Anambra State, Nigeria. J. Agric. Ext. Abstr. 23, 161, 2019.

31. BBS. Statistical Yearbook of Bangladesh. Dhaka, Bangladesh, 2012.

32. ALAM G.M., ALAM K., MUSHTAQ S. Influence of institutional access and social capital on adaptation decision: Empirical evidence from hazard-prone rural households in Bangladesh. Ecol. Econ. 130, 243, 2016.

33. ALAM G.M.M. Livelihood Cycle and Vulnerability of Rural Households to Climate Change and Hazards in Bangladesh. Environ. Manage. 59, 777, 2017.

34. YAMANE T. Statistics: An Introductory Analysis. Harper and Row, 1967.

35. ADGER W.N., VINCENT K. Uncertainty in adaptive capacity. Comptes Rendus Geosci. 337, 399, 2005.

36. ADGER W.N. Vulnerability. Glob. Environ. Chang. 16, 268, 2006.

37. MILleY P., JIWANI F. Resilience and Public Administration: Implications for the "New Political Governance" in Canada. Second World Congr. Resil. From Pers. To Soc. 811, 2014.

38. ALAM G.M.M. An assessment of the livelihood vulnerability of the riverbank erosion hazard and its impact on food security for rural households in Bangladesh. Phd Dissertation, University of Southern Queensland, Toowoomba, Australia, 2016. 
